\title{
Electro Cardio Graphic Changes in New and Treated Cases of Pulmonary Tuberculosis
}

\author{
Manoranjan Dash'1, Pravati Dutta², Narayan Mishra \\ ${ }^{1}$ Assistant Professor, Department of Pulmonary Medicine, SCB Medical College, Cuttack, Odisha, India. \\ 2Professor \& Head, ${ }^{3}$ Ex. Professor \& Head, Department of Pulmonary Medicine, VSS Medical College, Burla, Odisha, India.
}

\section{ABSTRACT}

Because of systemic nature of pulmonary tuberculosis and the closer relationship of heart and lung both anatomically and physiologically.it is natural to expect a greater involvement of heart in case of pulmonary tuberculosis Inspite of greater advances in the field of pulmonary tuberculosis and cardiology there are very few references in the world literature on ECG changes in pulmonary tuberculosis. The study was conducted by taking the cases who have attended the dept. of pulmonary medicine, VSS medical college, Burla, Odisha from June 2005 to July 2007. Study was aimed to know the cardio logical status in both new and treated cases of pulmonary tuberculosis reflected on electro cardiograph and to detect cor pulmonale changes in pulmonary tuberculosis.

50 newly diagnosed sputum smear positive patients of pulmonary tuberculosis or sputum positive cases who have taken treatment of $<2$ weeks duration were included in the study as new cases. 50 sputum smear positive patients who have completed full course of ATT and declared cured were taken as treated cases. After verbal consent all the cases were subjected to detailed history taking, physical examination followed by radiological and sputum AFB examination, after that routine investigations like $\mathrm{Hb}, \mathrm{DC}, \mathrm{TLC}, \mathrm{ESR}, \mathrm{FBS}$, lipid profile,urine,stool examination were done.

Finally a standard 12 lead ECG was taken in supine position in an empty stomach.

\section{INTRODUCTION}

Pulmonary tuberculosis is a very extensive diseases and destroys many respiratory units of lung even the tuberculosis process heals the fibrosed areas, cystic cavities or large emphysematous bullae persists. Such areas are poorly perfused and the gaseous exchanges in these areas is small and negligible which can lead to rise in the pressure in the pulmonary vasculature and subsequently leads to increase in stress in the right ventricle ad ultimately to cor pulmonale.death in acute form of tuberculosis is due to toxaemia leading to TB meningitis and miliary tuberculosis. But in chronic form complications like massive haemoptysis, suppuration and right heart failure etc. are likely causes.

Because of systemic nature of the disease and the closer relationship of heart and lung both anatomically and physiologically.it is natural to expect a greater involvement of heart in case of pulmonary tuberculosis. Tuberculosis is the commonest causes of pericarditis and pericardial effusion. More than half of the cases of constrictive pericarditis are also due to tuberculosis.TB myocarditis is a distinct entity and invariably secondary to tuberculosis of mediastinal lymph node or TB pericarditis. So it was considerably advised by SAILING SIMON and FELIX BAUM ${ }^{1}$ in 1928 to employ electro cardiograph for
There is significant changes in ECG in terms of heart rate, Rhythm, Axis, rotation, P wave, QRS complex, ST and T wave changes. Definite cor pulmonale changes in ECG was seen in 2 no. of $(4 \%)$ of new cases and 4 no. $(8 \%)$ in treated cases of pulmonary tuberculosis.

So finally it was seen that total ECG abnormalities seen in $64 \%$ of new cases and $36 \%$ of treated cases of pulmonary tuberculosis

Key words: ECG, Corpulmonale, Pulmonary tuberculosis.

\section{${ }^{*}$ Correspondence to:}

Dr. Manoranjan Dash,

Assistant Professor, Department of Pulmonary Medicine, SCB Medical College, Cuttack, Odisha, India.

Article History:

Received: 19-05-2016, Revised: 25-05-2016, Accepted: 18-07-2016

\begin{tabular}{|l|c|}
\hline \multicolumn{2}{|c|}{ Access this article online } \\
\hline Website: & Quick Response code \\
www.ijmrp.com & \\
\hline DOI: & \\
10.21276/ijmrp.2016.2.4.021 & \\
\hline
\end{tabular}

studying cases of chronic tuberculosis. Alteration in rate, rhythm, segmental $T$ wave, axis deviation, low voltage have been hypothesised. Several nomenclature have been suggested to denote involvement of heart secondary to pulmonary disease. Some author explains the ECG changes correlated with the degree of toxaemia, airflow limitation and direct myocardial involvements, fever and toxaemia, air flow limitation and direct myocardial involvement, fever and toxaemia influence the blood resistivity which leads to BROODY effect producing changes in QRS complex voltages. Inspite of greater advances in the field of pulmonary tuberculosis and cardiology there are very few references in the world literature on ECG changes in pulmonary tuberculosis.

\section{MATERIALS AND METHODS}

The study was conducted by taking the cases who have attended the Department of pulmonary medicine, VSS medical college, Burla from June 2005 to July 2007 . Study was aimed to know the cardio logical status in both new and treated cases of pulmonary tuberculosis reflected on electro cardiograph and to detect cor pulmonale changes in pulmonary tuberculosis. 


\section{Selection criteria}

50 newly diagnosed sputum smear positive patients of pulmonary tuberculosis or sputum positive cases who have taken treatment of $<2$ weeks duration were included in the study as new cases. 50 sputum smear positive patients who have completed full course of ATT and declared cured were taken as treated cases.

\section{Exclusion criteria}

Patients having cardiac diseases, DM, hypertension or under cardiac glycosides were excluded. Also pregnant ladies, patients having severe anemia and pleural complications were excluded.

After verbal consent all the cases were subjected to detailed history taking, physical examination followed by radiological and sputum AFB examination, after that routine investigations like $\mathrm{Hb}, \mathrm{DC}, \mathrm{TLC}, \mathrm{ESR}, \mathrm{FBS}$,lipid profile, urine,stool examination were done.

Finally a standard 12 lead ECG was taken in supine position in an empty stomach.

\section{RESULTS}

Majority of new cases belong to the age group of 25 to 54 years $(78 \%)$ and male to female ratio is $3.54: 1$. In treated case also majority of age groups 25 to 54 years $(68 \%)$ and the male to female ratio is 1.94:1.

The radiological extend of lesions in new cases seen is minimal in $30 \%$,moderate advanced in $46 \%$ and far advanced in $24 \%$ of cases. But in treated cases minimal radiological lesion seen in $24 \%$, moderate advanced $40 \%$ and far advanced in $36 \%$ of cases. Sinus tachycardia is present in $54 \%$ of new cases and $24 \%$ of treated cases but sinus bradycardia is seen in only $2 \%$ of new patients and none in treated cases. Majority of axis of qrs complex is $60 \mathrm{deg}$ in $74 \%$ of new cases and $68 \%$ in treated cases. The right axis deviation was seen in $12 \%$ of new cases and $10 \%$ of treated cases. Clock wise rotation was seen in $8 \%$ of new cases and $10 \%$ of treated cases but counter clock wise rotation was seen in $4 \%$ of new and $8 \%$ of treated cases. But in $88 \%$ of new and $82 \%$ of treated cases showed no rotation of heart.

$P$ wave voltage more than $2.5 \mathrm{~mm}$ is seen in $4 \%$ of new cases and $8 \%$ of treated cases. But definite p pulmonale was seen in 4 $\%$ of new and $8 \%$ of treated cases.

The low voltage QRS complex was seen in $10 \%$ of new cases and $14 \%$ of treated cases .rest had normal QRS voltage complex.

In new cases right ventricular hypertrophy was seen in $6 \%$ of cases, left ventricular hypertrophy was seen in $4 \%$ of cases. But in treated cases $8 \%$ showed right ventricular hypertrophy, $2 \%$ show left ventricular hypertrophy and in $2 \%$ cases show biventricular hypertrophy.

$8 \%$ of new cases showed ST segment depression and $2 \%$ showed ST segment elevation. But in $6 \%$ of treated cases we found ST depression and $2 \%$ of cases we found ST elevation.

In $6 \%$ of new cases and $10 \%$ of treated cases we got right bundle branch block. But none showed left bundle branch block.

T wave inversion was seen in $16 \%$ of new cases and $14 \%$ of treated cases. But flat T wave was seen in $10 \%$ of new cases and $8 \%$ of treated cases.

ECG abnormalities was seen in $100 \%$ in far advanced radiological lesions, $60 \%$ in Moderate advanced lesions and $47.8 \%$ in minimal radiological lesions. But in treated cases ECG abnormalities were seen in $50 \%$ cases of far advanced lesions, $35 \%$ of moderate advanced and $16.6 \%$ cases of minimal radiological lesions.
Definite cor pulmonale changes in ECG was seen in 2 no. of (4\%) of new cases and 4 no. (8\%) in treated cases of pulmonary tuberculosis.

So finally it was seen that total ECG abnormalities seen in $64 \%$ of new cases and $36 \%$ of treated cases of pulmonary tuberculosis.

\section{DISCUSSION AND CONCLUSIONS}

In this study we got sinus tachycardia in $54 \%$ of new cases of pulmonary tuberculosis and $24 \%$ of treated cases. This is higher than the studies done earlier by B.K Khanna $(1969)^{2}$ who observed this in $47.5 \%$ of new cases and $11.8 \%$ of treated cases. Gouretal (1994) (3) who found it in $42.7 \%$ of new cases and $11.8 \%$ of treated cases. The higher findings in our studies may be due to more number of associated pulmonary fibrosis. In our study we got sinus bradycardia in one cases which is also consistent with the study done by B.K Khanna (1969) ${ }^{2}$ and Gour etal $(1994)^{3}$ who also found in one case.

The majority of axis of QRS complex is 60 deg in $74 \%$ of new cases and $68 \%$ in treated cases. The right axis deviation was seen in $12 \%$ of new cases and $10 \%$ of treated cases. This study is nearly consistent with the earlier studies by Heaton etal $(1933)^{4}$ who found right axis deviation in $7.9 \%$ of cases, B.K Khanna $(1969)^{2}$ he found it in $7.5 \%$ of new cases and $12 \%$ of treated cases and Gour etal $(1994)^{4}$ who found it in $10 \%$ of cases. In our study we got low voltage in $10 \%$ of new cases and $14 \%$ of treated cases which is comparable to earlier study done by B.K Khanna $(1969)^{2}$ who got it in $7.5 \%$ of cases and Gour etal ${ }^{3}$ in $6 \%$ of cases.

$P$ wave voltage more than $2.5 \mathrm{~mm}$ was seen in $4 \%$ of new cases and $8 \%$ of treated cases which is comparable to the earlier study done by Gour etal $(1994)^{3}$ and Deepak et al (2002) who got this $6.7 \%$ of cases.

Right ventricular hypertrophy was seen in $8 \%$ of treated cases and $6 \%$ of new cases, left ventricular hypertrophy was seen in $2 \%$ of treated cases and $4 \%$ of new cases and biventricular hypertrophy was seen in $2 \%$ of treated cases. This can be comparable to the study done by Simon and Baum (1928) ${ }^{5}$ found right ventricular hypertrophy in $10 \%$ of the cases.

Our study is also nearly similar to that finding of Padmavati and Pathak (1959) 6 and Mishra $(1969)^{7}$ who found right ventricular hypertrophy in $5.5 \%$ and $7 \%$ of cases. Our study is also comparable to the study by chaterjee et al $(1971)^{8}$ and Agarwal et al $(1978)^{9}$ who got bi ventricular hypertrophy in $2 \%$ of cases.

Our study shows ST segment depression in $8 \%$ of new cases and $6 \%$ of treated cases which is slight higher to the observation done by Deepak et al $(2001)^{10}$ who found it in $3.3 \%$ of cases. This may be due to concomitant ventricular hypertrophy or may be due to more no. of extensive lesions.

Definite cor pulmonale changes in ECG was seen in $2(4 \%)$ of new cases and $4(8 \%)$ in treated cases of pulmonary tuberculosis. This finding is similar to the studies done padmavati and Pathak etal $(1959)^{5}$ who found it in $5.5 \%$ of cases. Shankar etal $(1974)^{11}$ found it in $6 \%$ of cases. Jain et al (1978) 12 found it in $8.8 \%$ of cases and Krisnna swamy et al (1980) ${ }^{13}$ found it in $5.1 \%$ of cases. It was seen that total ECG abnormality was in $64 \%$ in new cases and $36 \%$ in treated cases. This is slightly higher to the earlier study done by Gour et al (1994) ${ }^{3}$ who found ECG abnormality in 51 no of cases out of 110 patients $(46.4 \%)$ with substantial no. of 
reversibility in treated cases. The higher ECG abnormality may be due to more no. of extensive lesions in our study groups.

The exact mechanism of electrocardiographic changes in pulmonary tuberculosis is uncertain. However the possible explanation could be fever, toxaemia, Broody's effect, direct myocardial involvements, enlarged lymph nodes causing irritation of autonomic nerve fibres in the hilum and consequently altered sympathetic tone. The persistence of ECG abnormalities in treated cases is attributed to the positional disturbances of heart and mediastinum secondary to pulmonary fibrosis in extensive disease.

The development of cor pulmonale is secondary to pulmonary hypertension. This in turn has attributed to extensive blockage of pulmonary vascular bed and its destruction and restriction with consequent impairment of gaseous exchange, hypoxia and hypercapnea.

Corpulmonale is a serious complication or sequel associated with moderate or far advanced lesions in pulmonary tuberculosis.it can be avoided only if patients with pulmonary tuberculosis gets anti tubercular treatment as early as possible.

\section{REFERENCES}

1: Sailing and Simon: ECG changes in pulmonary tuberculosis

2: Khanna, B.K. 1969: ECG studies in pulmonary tuberculosis, ind. chest dis;11: 96-105.

3: Gour, S.N Singh, V.K. Banavaliker, J.N. Arsad, N (1994): influences of anti-tubercular chemotherapy on ECG changes in pulmonary tuberculosis, ind.J ,tubercle.1994;41:135-138.

4: Heaton, T.G (1933): Electro cardiographic changes in pulmonary tuberculosis,canad.med.association.J;29:294.

5: Electro cardiographic studies in chronic pulmonary tuberculosis by simon and Baum etal 1928.
6: Cor pulmonale in pulmonary tuberculosis by padmabati and Pathak-1959.

7: Padmavati Mishra (1969): Cor pulmonale in chronic pulmonary tuberculosis, J.Asso. phy. india 1969:17;363.

8: Chaterjee. P.K, lahiri, Sandeep, K.Pal, B.K (1971); ind. heart journal 22:265

9: Agarwal et al: Cor pulmonale in pulmonary tuberculosis J.I.M.A:1978:4

10: Deepak et al: effect of chemotherapy on ECG changes in Pulmonary tuberculosis presented at NAPCON 2001.

11: sankar, P.S . Antani, JA (1974): Advances in chronic obstructive lung diseases, edited by R.Viswanathan and O.P Jaggi.

12: Jain, P.K Agarwal, BV Jha, V.K singh, RG (1978): elactro cardio graphic leads in the diagnosis of cor pulmonale in pulmonary tuberculosis, j.Assoc.phy.ind:1978:71:4.

13: Cor pulmonale in pulmonary tuberculosis by Krishna swamy et al -ind .j of chest diseases 1973.

Source of Support: Nil. Conflict of Interest: None Declared.

Copyright: (c) the author(s) and publisher. IJMRP is an official publication of Ibn Sina Academy of Medieval Medicine \& Sciences, registered in 2001 under Indian Trusts Act, 1882.

This is an open access article distributed under the terms of the Creative Commons Attribution Non-commercial License, which permits unrestricted non-commercial use, distribution, and reproduction in any medium, provided the original work is properly cited.

Cite this article as: Manoranjan Dash, Pravati Dutta, Narayan Mishra. Electro Cardio Graphic Changes in New and Treated Cases of Pulmonary Tuberculosis. Int J Med Res Prof. 2016; 2(4):88-90. 